\title{
Climate control in historic buildings in Denmark
}

\author{
Poul Klenz Larsen ${ }^{1, *}$, Tor Broström² \\ ${ }^{1}$ The National Museum, Department of Conservation, Copenhagen, Denmark \\ ${ }^{2}$ Gotland University, Visby, Sweden \\ * Corresponding author. Tel: +45 33473533, Fax: +45 33473327, E-mail: poul.klenz.larsen@natmus.dk
}

\begin{abstract}
In many historic buildings, conservation heating has been used to control the RH in winter. Heat pumps are much more energy efficient than direct electric heating, so this technology may be adapted for climate control. Dehumidification has not been regarded as appropriate for historic buildings due to poor regulation, but recent development in electronic hygrostats makes this technology an attractive alternative. The annual energy consumption for both control strategies was calculated from statistical meteorological data for Denmark. The most energy efficient control strategy is determined by the U-value of the building, the air exchange rate and the volume. For large buildings conservation heating with heat pump technology seems to be the most energy efficient, unless the thermal insulation is very poor. For small buildings dehumidification is more efficient unless the building is very leaky. The two strategies for climate control were tested in historic houses owned by the National Museum in Denmark and used for exhibition only in the summer season. Kommandørgården has an uncontrolled climate in summer due to open doors in the opening hours. In winter the RH is controlled to 60$70 \%$ by hygrostatic heating. Liselund is an $18^{\text {th }}$ century mansion located in a romantic garden on the island Møn at the Baltic Sea. The house is open only for guided tours in the summer, and the RH is controlled all year by dehumidification.
\end{abstract}

Keywords: Dehumidification, conservation heating, air infiltration, historic building, climate control

\section{Introduction}

Denmark has a mild and humid coastal climate due to the influence of the Atlantic Ocean and the Gulf Stream. The average relative humidity is high, and frequent rainfall and mist from the sea is a source of humidity to any building. An ordinary house usually has a moderate RH inside due to heating and ventilation. But a historic building, which is not used for living or working anymore, has a high $\mathrm{RH}$ even if there is no human activity. The humidity comes from the outside air and in some cases also from rising damp or rain penetrating the walls. A permanent high RH has dramatic consequences for preservation of the interiors. Woodworms may eat up the furniture and moth will feed on the textiles if nothing is done to reduce the $\mathrm{RH}$. There are two options for a simple humidity control strategy in historic houses which are not permanently occupied by humans: Conservation heating or mechanical dehumidification. The question is which of the two strategies is the most energy efficient, and how to decide for the one or the other. In the present paper the question is dealt with through energy calculation of a generic building and a case study of two Danish buildings: Kommandørgården is a traditional farmhouse on the island Rømø, and Liselund is a mansion located on the island Møn.

Conservation heating is a well established practice to control the relative humidity for preservation purposes [Staniforth et al 1994]. It is a simple and robust method, but the stability of RH depends on the air infiltration rate and the temperature control. A leaky house with a thermostatic control will experience large variations in RH. Hygrostatic control is more flexible, but may suffer the problem of positive feedback due to evaporation from damp walls or floors. Another peculiar aspect of conservation heating is that heating is required also in summer to maintain a moderate RH. The summer heating may be avoided if the house has large south facing windows [Rademacher 2010]. As energy conservation becomes more and more important, heating all year is less attractive for climate control. The heat loss is much larger from historic buildings than from modern houses due to poor thermal insulation of 
walls and ceilings. Leaky doors and windows further increase the heat loss. In a historic house, the potential to improve the thermal performance is limited. Instead, the source of energy must be efficient. Electric heaters are frequently used because they need little installation work. Heat pumps are much more energy efficient, so this technology might be adapted for use in historic buildings [Brostrom and Leijonhuvud, 2008].

Dehumidification has until recently not been regarded as an appropriate control method due to the risk of damage caused by too much drying. Surely old fashioned dehumidifiers without proper RH control used in buildings sites were not suitable for historic houses. But the development of electronic hygrostatic control has made dehumidifiers an attractive alternative for historic buildings, where heating is not needed for human comfort. There are two methods for dehumidification of atmospheric air; absorption and condensing. The condensing dehumidifier contains the same elements as a refrigerator, but in a different combination: A fan drags the air through the cooling unit to extract the moisture, which drips into a bucket or to a drain. The cooled air then passes through the heating unit and back into the room a little warmer than before. This method works well in heated buildings but is less efficient below $8^{\circ} \mathrm{C}$. The absorption dehumidifier passes the air through a desiccant, usually silica gel, which absorbs the water vapour from the air. When the desiccant is full, a supply of warm air removes the moisture to the outside. The advantage of this method is that it works at low temperatures, even below zero degrees. The humidity is not transformed into a liquid, so the device does not need a drain or a bucked to be emptied. However, the device requires ducts for the release of the warm humid air to the outside.

\section{Theory}

A model building with a total volume of $500 \mathrm{~m}^{3}$ was used for the calculation of energy efficiency. The building had one level with a rectangular plan of $10 \times 17 \mathrm{~m}^{2}$ and $3 \mathrm{~m}$ to the ceiling. The U-value of the ceiling and the walls was $1.0 \mathrm{~W} / \mathrm{m}^{2} \mathrm{~K}$, which equals $50 \mathrm{~cm}$ solid brick masonry or $5 \mathrm{~cm}$ wood planks. The model did not take into account heat loss or gain from the floor. Solar radiation to the building and heat radiation to the open sky was not considered. The building was empty and had no internal sources of humidity. The only source of moisture into and out of the building was the outside air, which would enter at a constant rate. If nothing was done, the inside climate of the building would be almost the same as outside. But the RH was to be maintained constant at $60 \%$ all year, either by heating or by dehumidification. The calculation used the monthly averages of temperature and relative humidity in Denmark. For every month the appropriate temperature for conservation heating and the excess moisture to be removed by a dehumidifier was determined. These data are presented in table 1.

The energy needed for conservation heating and dehumidification as a function of the Air Exchange Rate (AER) is shown in Fig. 1. In the case of dehumidification (blue line) the energy demand depends only on the AER. It was assumed that an absorption dehumidifier would use $1 \mathrm{kWh}$ to remove one kg of water from the air. The energy was used to heat up the air stream that evaporated the moisture from the adsorbent. In the case of conservation heating (red line) the energy needed to achieve the target RH depends on the temperature difference between inside and outside. It is assumed that the heat pump gives of $3 \mathrm{kWh}$ of heat for each $\mathrm{kWh}$ of electric power (COP $=3$ ). As for dehumidification, the energy demand increases proportional to the AER. But even an airtight structure needs heating due to the heat loss by transmission thought the walls and ceiling. This depends on the U-value and defines the intersection with the Y-axis. The crossing point of the two straight lines divides the diagram into two segments. Dehumidification is more energy efficient than heating with a heat pump if 
the air exchange rate is lower than 1 per hour. At higher air exchange rates heating becomes more favorable. The heat loss from a highly insulated building $\left(U=0.1 \mathrm{~W} / \mathrm{m}^{2} \mathrm{~K}\right)$ and a very lightly build house ( $\mathrm{U}=2.0 \mathrm{~W} / \mathrm{m}^{2} \mathrm{~K}$ ) is shown for comparison. A heat pump is more energy efficient for climate control in a well insulated building if the AER is higher than 0.1 per hour, whereas dehumidification is favorable in a building with little thermal insulation if the AER is below 2 times per hour.

Table 1. Monthly average for outside temperature (Out T), relative humidity (Out RH) and outside absolute humidity (Out AH) for Denmark. Estimated inside temperature (In T) and temperature difference ( $T$ dif) for conservation heating to a constant $R H$ at $60 \%$. Estimated inside absolute humidity (In AH) and difference in absolute humidity (AH dif) for dehumidification to a constant $60 \%$ RH.

\begin{tabular}{|c|c|c|c|c|c|c|c|}
\hline \multirow[b]{2}{*}{ Month } & \multicolumn{3}{|c|}{ Meteorological data } & \multicolumn{2}{|c|}{ Conservation heat } & \multicolumn{2}{|c|}{ Dehumidification } \\
\hline & $\begin{array}{l}\text { Out T } \\
\left({ }^{\circ} \mathrm{C}\right)\end{array}$ & $\begin{array}{c}\text { Out RH } \\
(\%)\end{array}$ & $\begin{array}{l}\text { Out AH } \\
\left(\mathrm{g} / \mathrm{m}^{3}\right)\end{array}$ & $\begin{array}{l}\text { In T } \\
\left({ }^{\circ} \mathrm{C}\right)\end{array}$ & $\begin{array}{l}\mathrm{T} \text { dif } \\
\left({ }^{\circ} \mathrm{C}\right)\end{array}$ & $\begin{array}{l}\text { In } \mathrm{AH} \\
\left(\mathrm{g} / \mathrm{m}^{3}\right)\end{array}$ & $\begin{array}{l}\text { AH dif } \\
\left(\mathrm{g} / \mathrm{m}^{3}\right)\end{array}$ \\
\hline Jan & 0 & 87 & 4.2 & 5.5 & 5.5 & 2.9 & 1.3 \\
\hline Feb & 0 & 85 & 4.1 & 5.0 & 5.0 & 2.9 & 1.2 \\
\hline Mar & 2 & 83 & 4.6 & 7.0 & 5.0 & 3.4 & 1.2 \\
\hline Apr & 7 & 76 & 5.9 & 10.5 & 3.5 & 4.7 & 1.2 \\
\hline May & 12 & 68 & 7.2 & 14.0 & 2.0 & 6.4 & 0.8 \\
\hline Jun & 16 & 68 & 9.2 & 18.0 & 2.0 & 8.2 & 1.0 \\
\hline Jul & 18 & 71 & 10.8 & 21.0 & 3.0 & 9.1 & 1.7 \\
\hline Aug & 17 & 74 & 12,0 & 22.5 & 5.5 & 8.7 & 3.3 \\
\hline Sep & 14 & 78 & 9.4 & 18.5 & 4.5 & 7.2 & 2.2 \\
\hline Oct & 9 & 83 & 7.3 & 14.0 & 5.0 & 5.3 & 2.0 \\
\hline Nov & 5 & 87 & 5.9 & 11.0 & 6.0 & 4.1 & 1.8 \\
\hline Dec & 3 & 88 & 5.2 & 9.0 & 6.0 & 3.6 & 1.6 \\
\hline
\end{tabular}

For every U-value there is an AER, at which heating and dehumidification is equally efficient. The relation between AER and U-value is linear as shown in Fig. 2. If a building with $500 \mathrm{~m}^{3}$ volume has a combination of AER and U-value above the blue line, then dehumidification is the most efficient way to control the $\mathrm{RH}$ to $60 \%$ over the year. This is typical for historic buildings which are not used for living or working. If the combination of AER and U-value is below the blue line, then a heat pump is more efficient for climate control. Modern buildings which are ventilated for human comfort are in this segment. Similar lines for equal energy efficiency is shown for a large building $\left(2000 \mathrm{~m}^{3}\right)$ and a small building $\left(100 \mathrm{~m}^{3}\right)$. Heating is favorable for most combinations in a large building, whereas dehumidification is more efficient in small buildings for most combinations of AER and U-value. 


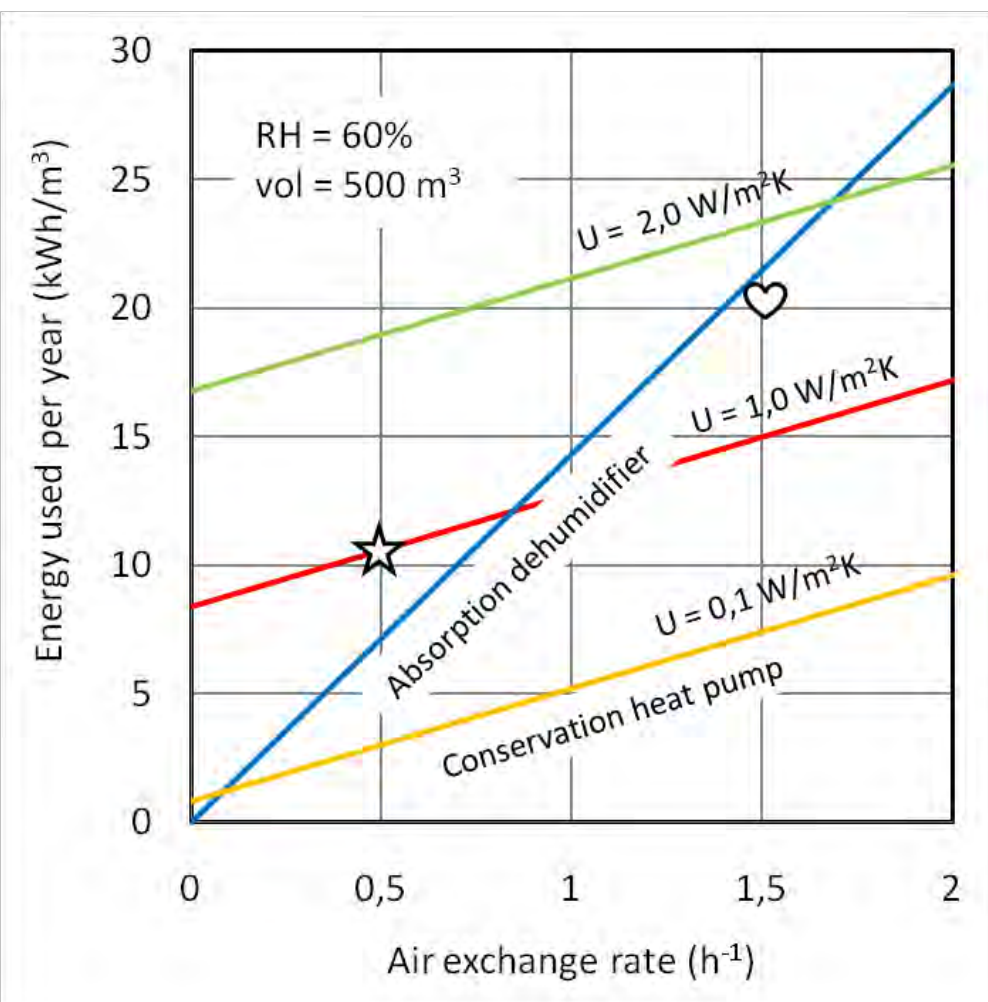

Fig. 1. The energy used per year by two different strategies to control the relative humidity to $60 \%$ in a $500 \mathrm{~m}^{3}$ building. The calculations were based on monthly statistic data presented in tab. 1 . The star represents Kommandørgården and the heart represents Liselund.

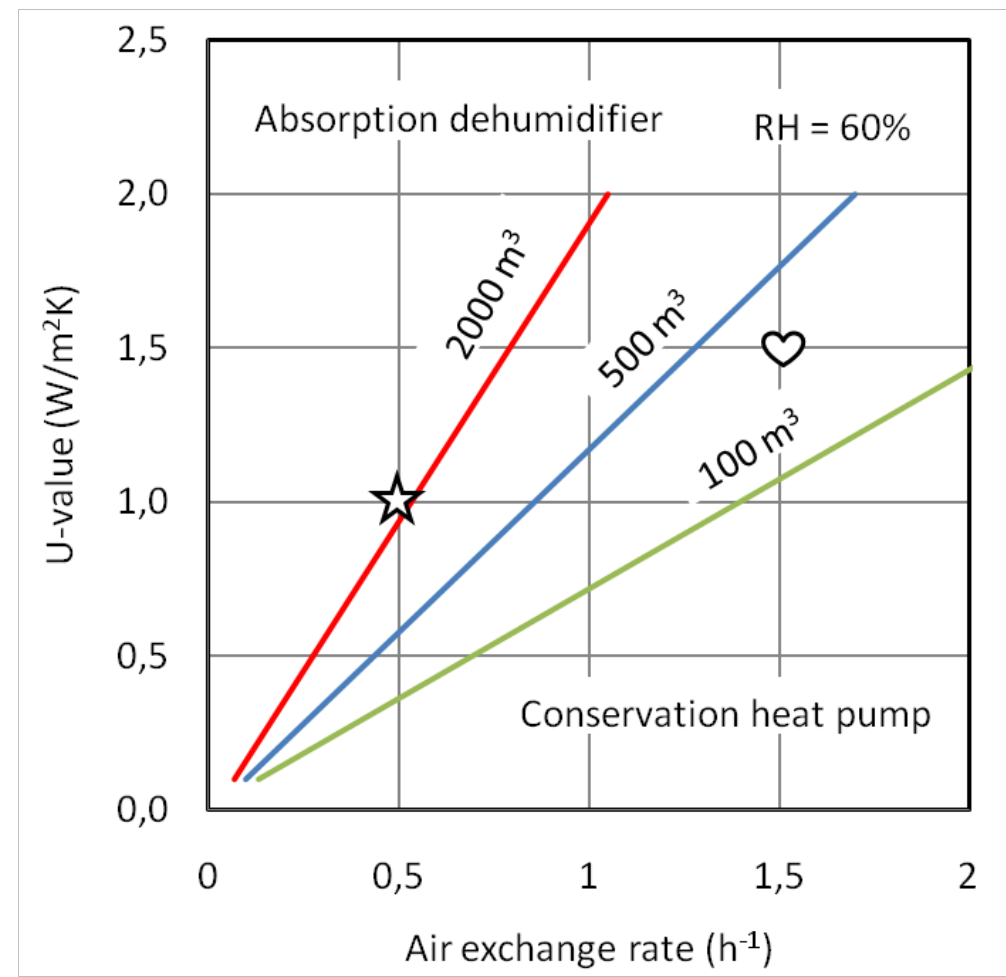

Fig. 2. Lines of equal energy efficiency with dehumidification and heating by a heat pump for controlling the RH to $60 \%$. The size of the building is indicated for each line. The star represents Kommandørgården and the heart represents Liselund. 


\section{Conservation heating at Kommandørgården}

The concept of conservation heating was implemented in Kommandørgården (Fig.3). The traditional farmhouse is located on the island Rømø at the west coast of Jylland, exposed to the strong winds from the North Sea. The building has solid walls of brick masonry with wooden panels or glazed tiles on the inside. The floors and ceilings are wooden planks and the roof is thatched. The average U-value of the walls and ceiling is $1.0 \mathrm{~W} / \mathrm{m}^{2} \mathrm{~K}$. The volume of the ground floor is $250 \mathrm{~m}^{3}$. It is used as an open air museum in summer, and climate control is not possible due to the many visitors during the day. In the winter 2006 conservation heating was introduced with portable heating fans in the three main rooms. Each heater was controlled by a hygrostatic switch placed in some distance from the warm air stream. Climate records for 1 January to 1 July 2006 shows that the temperature was raised from $2-3{ }^{\circ} \mathrm{C}$ to $8-12{ }^{\circ} \mathrm{C}$, and the RH dropped from $90 \%$ to 65 - 55 \% (Fig. 4). The heating was stopped when the museum opened at the end of March, and the RH soon rose back above 80\%. The RH dropped to 60$70 \%$ again in the two first weeks of May, when the house was heated due to conservation works. This episode shows that conservation heating would be feasible also in the spring.

The air exchange rate in winter was measured by the PerFlour-Tracergas method (PFT) in collaboration with the Building Research Institute (Bergsøe). An inert fluorcarbon gas was emitted at a constant rate to the interior from metal tubes distributed in the rooms. The gas was collected by glass tube samplers mounted in distance from the emission tubes. The amount of gas collected over a 4 weeks period was a measure of the average concentration, which depended on the infiltration of outside air. Usually the procedure should be repeated both in summer and winter to account for the different outside conditions, but in this case the measurement was done only in February, where the AER was $0.5 \mathrm{~h}^{-1}$. This result is plotted with a star in the diagrams in Fig. 1 and 2. From Fig. 2 it seems that dehumidification would be more energy efficient for controlling the RH in winter, and perhaps also in summer if an air lock was installed at the entrance.

\section{Dehumidification at Liselund Mansion}

Dehumidification has been used for climate control in Liselund mansion, which dates back to 1800. The building is situated at a small pond in a romantic park on the island Møn at the Baltic Sea (Fig. 5). The walls are $50 \mathrm{~cm}$ solid masonry and the roof is thatched. The floors are wooden planks and the ceiling is gypsum plaster. The building has large single glazed windows and doors, which take up $25 \%$ of the wall surface area. The volume of the basement and the ground floor is $650 \mathrm{~m}^{3}$ and the average U-value is $1.5 \mathrm{~W} / \mathrm{m}^{2} \mathrm{~K}$. In summer there are guided tours, but apart from that it remains closed all year.

The RH is controlled by an absorption dehumidifier (Munters) located in the basement. The dry air is distributed with ducts into each room through small grills in the floor. The air is returned though the staircase to the basement. The desiccant is embedded in a revolving unit, which enables the dehumidifier to work continuously. Absorption and evaporation takes place simultaneously from separate segments of the unit. The RH was 55-65\% all year, whereas the temperature was drifting from around $0{ }^{\circ} \mathrm{C}$ in winter to $20{ }^{\circ} \mathrm{C}$ in summer (Fig. 6). The annual energy consumption for dehumidification was $13 \mathrm{MWH}$ or $20 \mathrm{kWh}$ per $\mathrm{m}^{3}$ per year. The Air Exchange Rate was not measured, but can be estimated to $1.5 \mathrm{~h}^{-1}$ from Fig. 1 . The doors and windows are indeed rather leaky, and much energy would be saved by improving the air tightness of these components. 


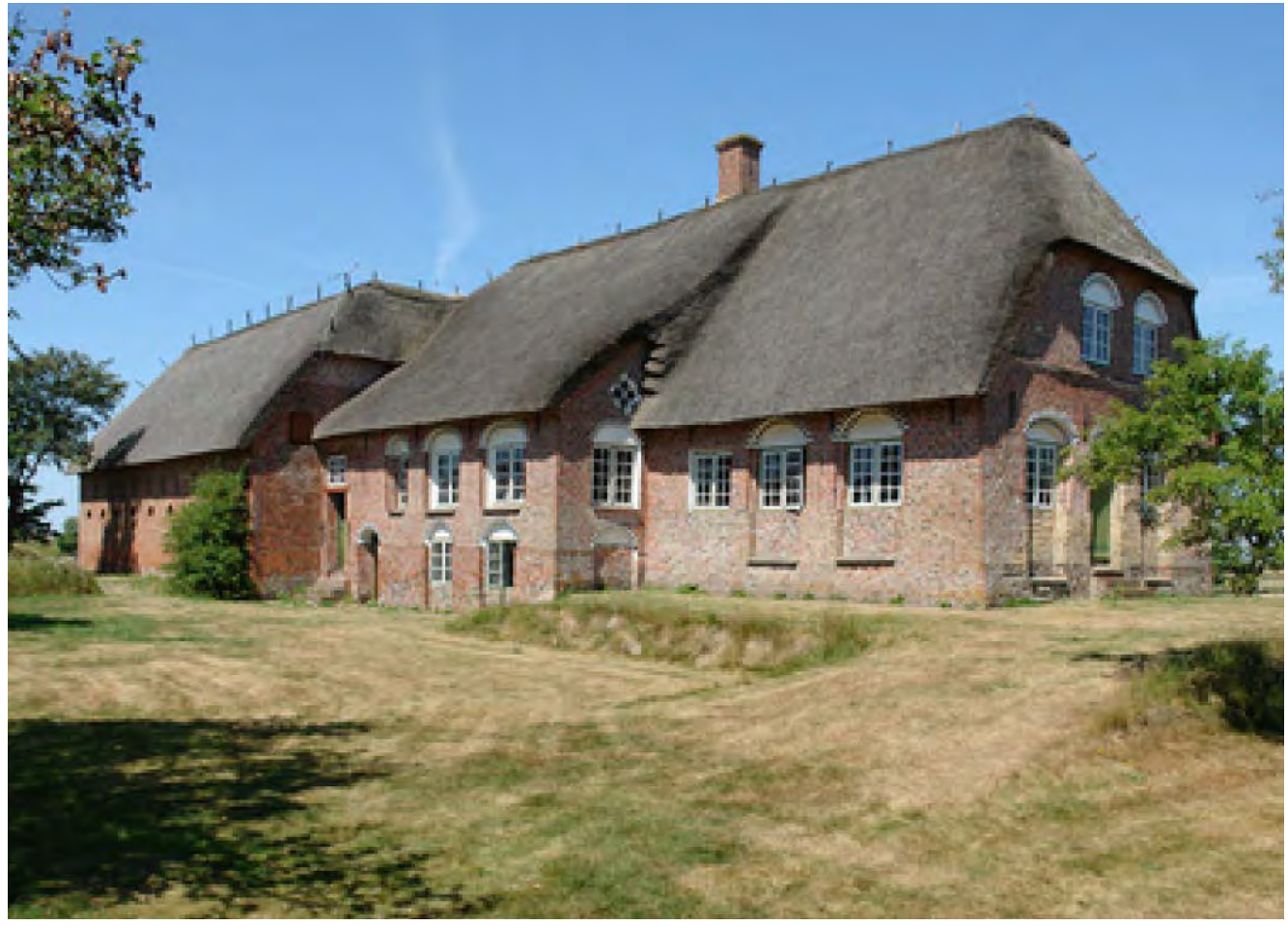

Fig. 3. View of Kommandørgården from the southeast. The traditional farmhouse is located on the island Rømø at the West coast of Jylland close to the North Sea.

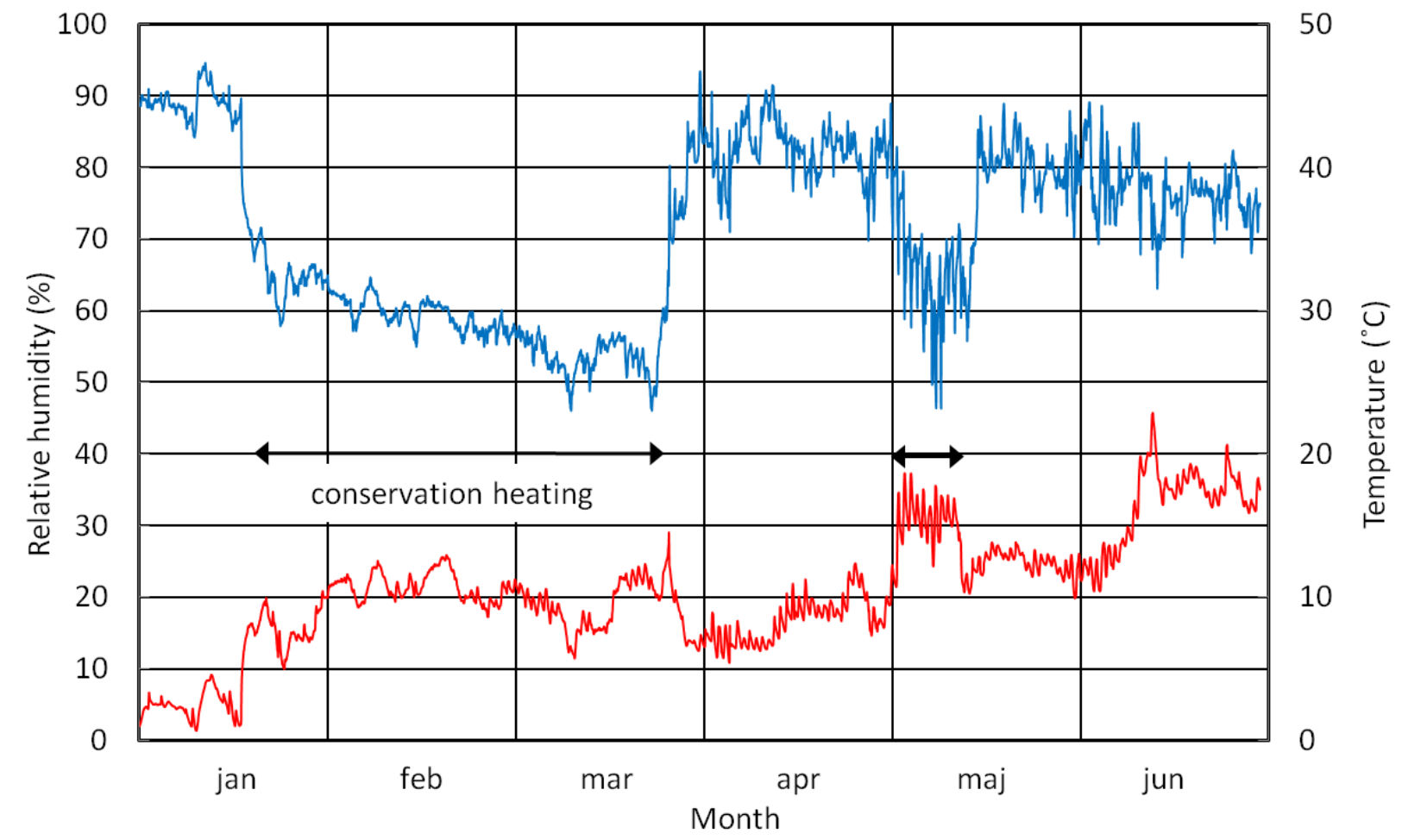

Fig. 4. Indoor climate records from Kommandørgården over six months in the winter and spring 2006. Conservation heating with hygrostatic control to $60 \%$ was started in mid January and terminated at the end of March when the museum opened for the Easter holidays. 


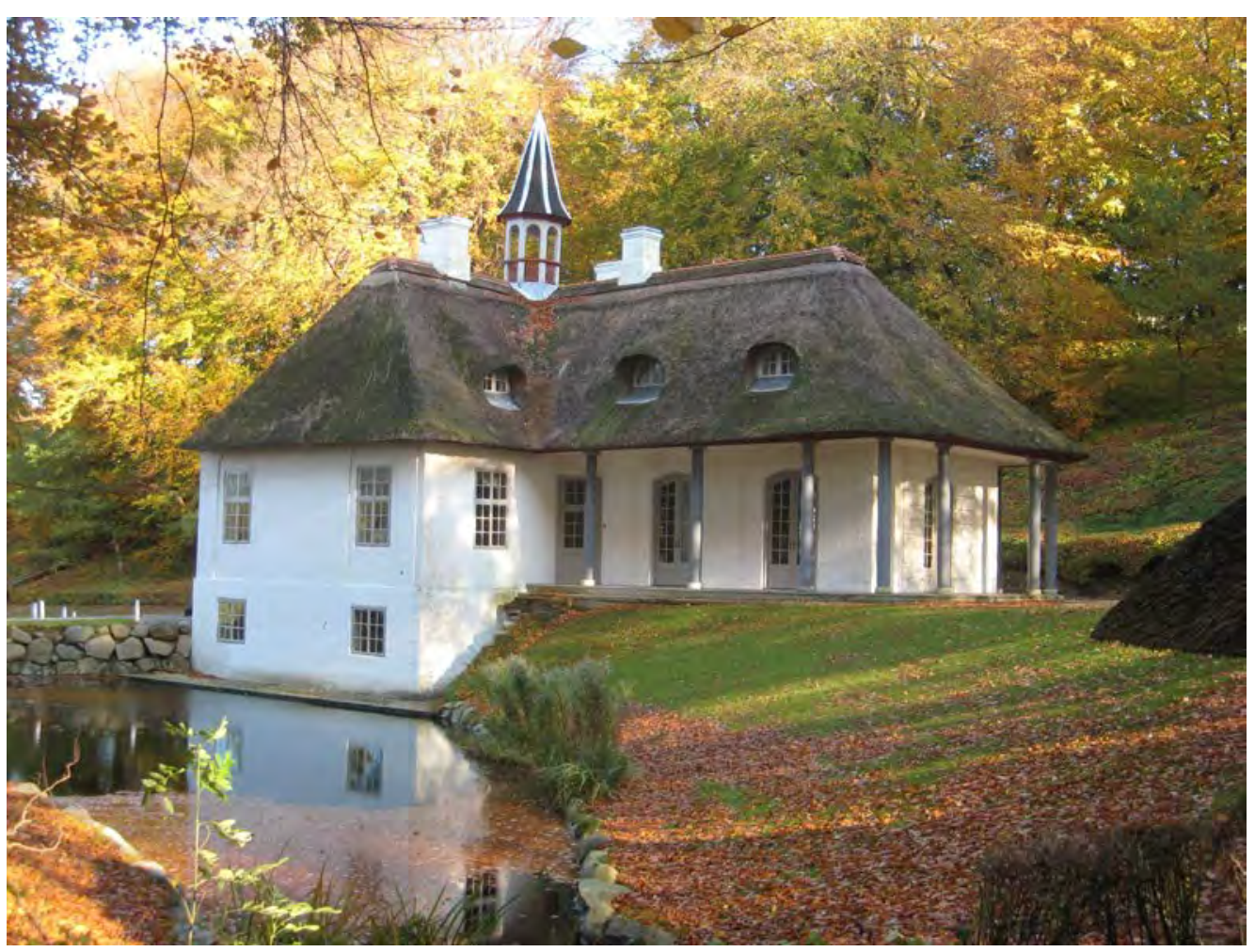

Fig. 5. View of Liselund Mansion from the southwest. The building is located in a romantic garden on the island Møn close to the Baltic Sea.

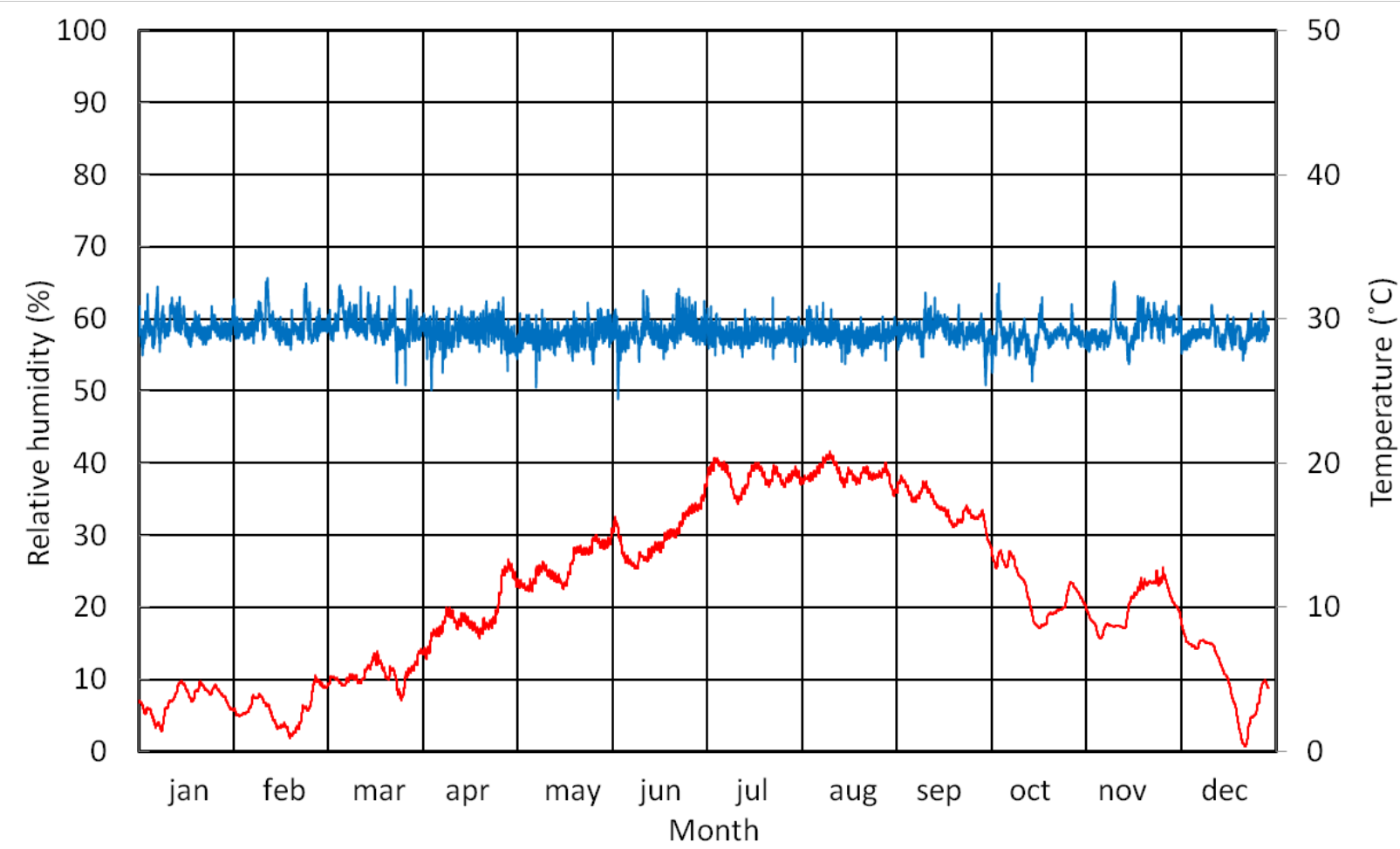

Fig. 6. Indoor climate records from Liselund Mansion in 2009. The relative humidity (RH) was controlled to 55- $65 \% R H$ by dehumidification. The indoor natural temperature variation was $0-20$ ${ }^{\circ} \mathrm{C}$ due to the influence of the outside temperature. 
The combination of U-value and estimated AER is plotted in Fig. 2 with a heart. According to this, conservation heating with a heat pump would be more energy efficient if nothing is done to reduce air infiltration. Another reason for the high energy consumption could be evaporation of moisture from the ground. The basement floor is only slightly above the water level of the pond outside. Such external sources of moisture are not included in the calculations and are a potential source of error.

\section{Conclusion}

The strategy for climate control in historic buildings depends on whether the house is occupied by humans or not. In many historic buildings, conservation heating has been used to control the $\mathrm{RH}$ in winter. But the heat loss is usually large, because historic buildings are leaky and have poor thermal insulation. It is difficult to improve the performance of the building envelope, so the energy source must be efficient. Heat pumps are much more energy efficient than direct electric heating, so this technology may be adapted for climate control. Dehumidification has not been regarded as appropriate for historic building, but better regulation makes this technology an attractive alternative. The paper gives a general method to determine the most energy efficient strategy for humidity control in relation to buildings characteristics. The most energy efficient control strategy is determined by the U-value of the building, the air exchange rate (AER) and the volume. For large buildings, conservation heating with heat pump technology seems to be the most energy efficient, unless the thermal insulation is very poor. For small buildings dehumidification is more efficient unless the building is very leaky. The results are only valid for locations with natural climatic conditions similar to Denmark. Further research will generalize the method and also take into account internal moisture sources as well as other types of dehumidifiers.

\section{References}

[1] S. Staniforth, B. Haves and L. Bullock, Appropriate Technologies for Relative Humidity Control for Museum Collections Housed in Historic Buildings, Preventive Conservation: Practice, Theory and Research, Preprints of the contributions to the Ottowa Congress. London, The International Institute for Conservation of Historic and Artistic Works (IIC), 1994, pp. $123-128$

[2] H. Rademacher, Feuchtegesteuerte Beheizung zur präventiven Konservierung einess Schlossmuseums, Klima und Klimastabilität in historichen Bauwerken, WissenschaftlichTechniche Arbeitsgemeinschaft für Bauwerkserhaltung e.V. Arbeitsgruppe 6.11., 2010, pp 77-88

[3] T. Brostrom, G. Leijonhufvud, Heat pumps for conservation heating, Nordic Symposium on Building Physics, Copenhagen, June 2008, pp

[4] N.C. Bergsøe, Passive tracer gas method for ventilation investigations. Description and analysis of the PFT-method, SBI report 227, Danish Building Research Institute, Hörsholm, 1992 